\title{
Experimental study of filtration activity in Ditrupa arietina (Annelida Polychaeta) using an automated image analysis system
}

\author{
Jean-Claude DUCHÊNE, Esther JORDANA, François CHARLES, Antoine GRÉMARE *, \\ Jean-Michel AMOUROUX
}

Observatoire océanologique de Banyuls, BP 44, 66651 Banyuls-sur-Mer cedex, France

Received 25 April 2000; revised 21 August 2000; accepted 22 August 2000

\begin{abstract}
An automated image analysis system designed to assess the activity of benthic organisms is described. This system is used to study filtration in the serpulid polychaete Ditrupa arietina. The video sensor of the system is composed of a black and white charged coupled device, a microprocessor, a memory and an interface board. It is driven by real-time routines, which are downloaded in permanent memory prior to each experiment. These routines control picture acquisition frequency and compute the differences in grey levels between the image recorded at a given time and a reference image (corresponding to no filtration in the case of $D$. arietina). These differences are used to detect numerical objects, which are stored in the memory board. At the end of each experiment, these objects are uploaded to a microcomputer where they are analysed using a second set of programs. This procedure involves several parameters, namely: the minimal object surface which is indicative of a real difference between two images (minimal surface), the research area (search radius), the research sites, and the definition of a set of conditions relating differences between images with a true filtering activity by $D$. arietina. These parameters were determined by comparing the results obtained using: 1) the automated system, and 2) classical frame by frame videotape analysis. They were then validated on several batches of worms by comparing total filtering durations per worm measured using the as previously calibrated automated system with those obtained using classical video observations. This step showed that the automated system is suitable for studying filtering activity in $D$. arietina. Our first results show that inter-individual variability is high, which has important consequences on experimental plans designed to assess the effects of environmental factors on filtration. (C) 2000 Ifremer/CNRS/IRD/Éditions scientifiques et médicales Elsevier SAS
\end{abstract}

\section{Polychaetes / image analysis / activity / filtration}

Résumé - Étude expérimentale de l'activité de filtration de Ditrupa arietina (Annélide Polychète) par l'intermédiaire d'un système d'analyse d'images automatisé. Un système d'analyse d'image automatisé conçu pour l'analyse de l'activité des organismes benthiques est décrit. Ce système est utilisé pour étudier la filtration de la polychète serpulidae Ditrupa arietina. Le capteur vidéo du système est composé d'un capteur optique CCD noir et blanc, d'un microprocesseur, d'une carte mémoire et d'une interface. Il est piloté, en temps réel, par des programmes chargés en mémoire permanente avant chaque expérience. Ces programmes contrôlent la fréquence d'acquisition des images et calculent les différences de niveaux de gris pour chacun des pixels composant l'image enregistrée à un temps donné et une image de référence (correspondant à l'absence totale de filtration dans le cas de Ditrupa arietina). Ces différences sont utilisées pour définir des objets numériques qui sont stockés en mémoire. A la fin

\footnotetext{
* Correspondence and reprints.

E-mail address: gremare@obs-banyuls.fr (A. Grémare).
}

(C) 2000 Ifremer/CNRS/IRD/Éditions scientifiques et médicales Elsevier SAS. Tous driots réservés. 
de chaque expérience, ces objets sont transférés dans un microordinateur où ils sont analysés à partir d'un deuxième jeu de programmes. Cette procédure fait intervenir plusieurs paramètres: la surface minimale indicatrice d'une différence réelle entre deux images (surface minimale), l'aire de recherche (rayon de recherche), les sites de recherche, et la définition d'un jeu de conditions mettant en relation les différences entre images et une activité de filtration réelle de $D$. arietina. Ces paramètres ont été déterminés par comparaison des résultats obtenus à partir : (1) du système automatisé, et (2) d'enregistrements vidéo classiques. Ils ont ensuite été validés sur plusieurs lots d'animaux en comparant les activités individuelles mesurées à l'aide du système vidéo ainsi calibré avec celles résultant de l'analyse d'enregistrements vidéo. Cette étape a montré que le système est adapté à l'étude de l'activité de filtration de $D$. arietina. Nos premiers résultats montrent que la variabilité interindividuelle est grande ce qui induit des conséquences importantes sur les plans expérimentaux destinés à mettre en évidence les effets des facteurs environnementaux sur l'activité de filtration. (C) 2000 Ifremer/CNRS/IRD/Éditions scientifiques et médicales Elsevier SAS

\section{Polychètes / analyse d'images / activité / filtration}

\section{INTRODUCTION}

Recent investigations carried out in the bay of Banyuls-sur-Mer have shown major changes in macrobenthos species composition (Grémare et al., 1998a). The most important one is linked to the increase of the serpulid polychaete Ditrupa arietina (O.F. Müller), which is now dominant in the two shallowest assemblages, namely the Spisula subtruncata and the Nephtys hombergii communities. Large scale study of the spatial distribution of $D$. arietina has shown that this species is now present in high densities all along the Catalan coast from Barcelona to Montpellier, whereas it was almost absent a quarter of century ago (Grémare et al., 1998b). The increase of $D$. arietina in the Gulf of Lions is thus at least of regional importance. This process has important ecological consequences. It may affect carbon cycle through calcification during tube building (Medernach et al., 2000). The replacement of the active filter-feeding bivalve $S$. subtruncata by the gill crown suspension-feeding polychaete $D$. arietina may also result in differences in benthic trophic network functioning, and more specifically in changes in particle transfers from the water column to the sediment through filtration and biodeposition.

D. arietina feeds on suspended particles by extending its gill crown in the overlaying water and quickly retracts it as soon as disturbed (Jordana, personal observation). Such an extreme sensitivity may constitute a difficulty when interpreting results of feeding experiments. More generally, and with the important exception of bivalves (Morton, 1983; Thorin et al.,
1998), only little quantitative information about benthic invertebrate's feeding activity or rhythm is yet available. Most of the existing data refer to tidal or diurnal rhythms (Grémare, 1987). However, feeding activity appears also affected by other factors such as food availability (Hill, 1976) or local hydrodynamics (Trager et al., 1990 and 1992; Achituv and Yamaguchi, 1997).

The assessment of feeding activity can be based on physiological measurements (Davey et al., 1990; DeVilliers and Hodgson, 1993) or on direct observations. In the latter case, it involves live visual observations (Grémare, 1987) or video-recordings (Trager et al., 1990; Achituv and Yamaguchi, 1997), which are both rather long and difficult to obtain and (or) to interpret. This may explain the relative lack of available data. A sound alternative consists in developing automated systems such as has already been done for the study of bacterial (Häder and Vogel, 1991), larval (Butman et al., 1988; Grassle and Butman, 1989; Duchêne and Nozais, 1994; Nozais and Duchêne, 1996; Nozais et al., 1997) or fish motions (Boisclair, 1992). The most important limitations of those systems are that they: (1) were mostly designed for organisms living in the water column, and (2) generally did not allow for in situ monitoring. We were thus interested in developing an automated image analysis system suitable for both in vitro and in situ monitoring of benthic organisms activity. The aim of this paper is to describe this equipment, and to report on the first results regarding filtering activity in D. arietina. 


\section{MATERIALS AND METHODS}

\subsection{The automated image analysis system}

The automated system is made of a video sensor coupled with a computer (figure 1A). The sensor (figure $1 B$ ) is composed of a charged coupled device (CCD), a processor, several memory boards and an interface board. The sensor is managed by real-time routines, which are downloaded from the computer to the permanent program memory at the beginning of each monitoring session. These routines perform image analysis in real time. At the end of the session, other programs implemented in the computer manage the recovery and the post-treatment of activity data. The two main interests of this system thus are: it provides a real-time analysis of the video fields, and

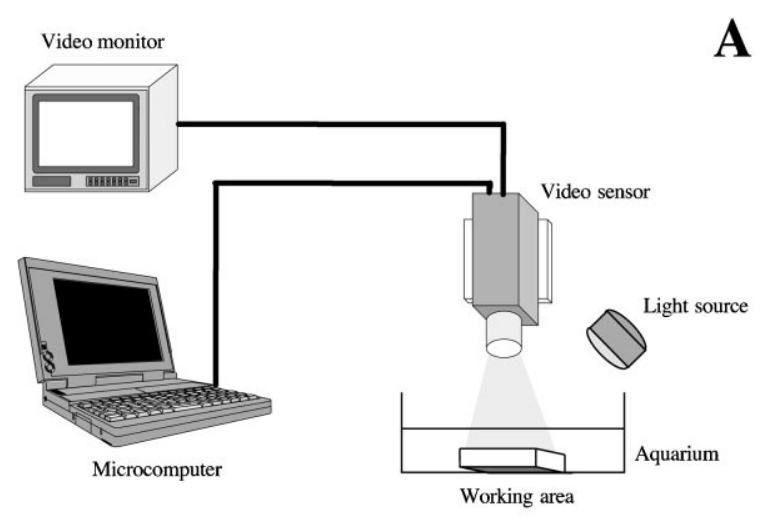

B

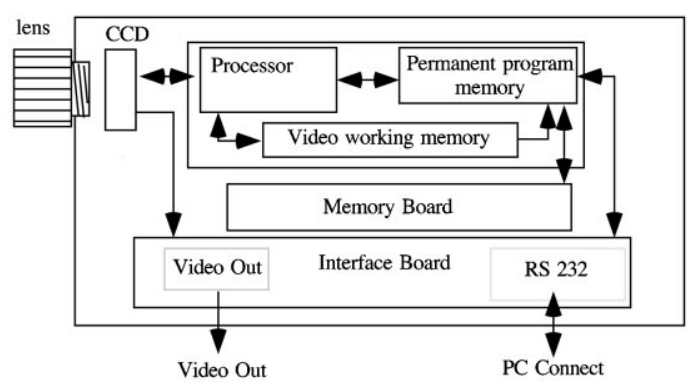

Figure 1. Schematic diagram of the automated image analysis system (A) and of the video-sensor (B). the sensor is fully autonomous during data acquisition.

\subsubsection{Hardware}

We used a CCD (VLSI Vision Ltd) with a resolution of $256 \times 256$ pixels and 256 levels of grey. The microprocessor collects data originating from the CCD sensor and transfers them at a 50 frames $\cdot \mathrm{s}^{-1}$ rate in a video working memory, which is then sampled according to a periodicity fixed by the operator during downloading. The images obtained are compared to a reference one. Differences between images are stored in a compacted format within the memory board together with the results of other computations carried out by the real-time routines. An interface board is used to connect the processor to the external computer through an RS 232 port. This board includes circuitry to reconstruct a video output signal. This video output is a regular CCIR 1Vcc composite signal, which is used to connect a video monitor, required to adjust the video field at the beginning of each experiment.

\subsubsection{Software}

The software required to manage the whole system includes both real-time routines and post-treatment programs. All these programs are written in $\mathrm{C}$ language and compiled in a micro-controller code within a library. This library is accessed through the installation program. A menu driven window selects the routines corresponding to the experiment from the library and sends them to the sensor through the serial interface. This download is done once for all at the beginning of each experiment. At the beginning of each session, the computer must thus be connected to the sensor in order to: (1) download real-time routines if not already present in the permanent memory, and (2) send the start command to the system. Measurements are then carried out automatically and the data (i.e., objects generated by real time routines based on differences in grey levels between the reference and the current image) are stored within the internal memory of the sensor. The microcomputer may thus be disconnected during data acquisition. However, at the end of the experiment, it must be connected once again to send a 'stop command' and to upload the data. Data are then processed by post-treatment programs based on three main parameters: minimal area, search radius, and research sites. 


\subsection{Biological material}

Worms were collected on several occasions between 1996 and 1998, either within the bay of Banyuls-surMer $(25 \mathrm{~m}<$ depth $<30 \mathrm{~m})$, or off Argelès-sur-Mer (26 m < depth $<29 \mathrm{~m}$ ), which is located about $20 \mathrm{~km}$ north. Back to the laboratory, they were placed in tanks $(\mathrm{L}: \mathrm{W}: \mathrm{H}, 2 \times 1 \times 0.2 \mathrm{~m})$ containing a thin layer of sand and fuelled with running ambient seawater.

\subsection{Calibration of the automated system}

On 16 January 1997, 15 worms, collected within the bay of Banyuls-sur-Mer were placed in an aquarium containing $30 \mathrm{~L}$ of filtered seawater $(1.5 \mu \mathrm{m})$. They were positioned upright in well calibrated fine sands covered by a fine layer of mud with the entry of their tube located about $1 \mathrm{~cm}$ above the water-sediment interface. Just prior to the start of the experiment, worms were induced to retract their gill crown and to close their tube aperture. The images obtained was used as reference (i.e., no filtration). The video sensor was positioned $14 \mathrm{~cm}$ above the sediment surface and the orientation of the light set so that activity could be assessed both around the tube apertures and around their shadows on the sediment. The duration of the experiment was $2 \mathrm{~h}\left(15^{\circ} \mathrm{C}\right)$, with the activity being recorded every minute. Individual worms activities were also recorded on videotapes that were analysed frame by frame for filtering activity.

Calibration consisted in determining the values of the four main parameters involved in the functioning of the post-treatment programs. We first considered minimal surface (2, 10 and 20 pixels), then search radius (5, 10, 15 and 20 pixels), and research sites (tube's aperture and shadow), and at last the set of parameters and conditions corresponding to filtration. In each case, different values were tested and corresponding total individual filtration durations were compared with those measured using classical video-recordings. Both the intercepts $(=0)$ and the slopes $(=1)$ of the linear regression models linking 'predicted' and 'observed' individual activities were tested.

\subsection{Validation of the automated system}

We used the same experimental protocol as for the calibration phase but with four different batches of
15 worms collected within the bay of Banyuls-surMer. The first three experiments were carried out between 6 and 18 December 1996. The fourth experiment was carried out on 3 November 1998. Total durations of filtering activity per worm were quantified using the set of parameters and conditions determined during the calibration phase. They were then compared with values derived from classical video-recordings. The statistical procedure was similar to the one used during the calibration phase.

\subsection{Analysis of filtering activity patterns in $D$. arietina}

Filtering activity patterns in $D$. arietina were described based on individual records obtained during three experiments carried out on 8, 9 and 10 September 1997. Each experiment $\left(16^{\circ} \mathrm{C}, 24 \mathrm{~h}\right.$, filtered seawater) involved a batch of twelve worms collected in front of Argelès-sur-Mer on 5 September 1997. We looked for trends in temporal changes of individual filtering activity using a simple smoothing average technique. We checked for periodicity using spectral analysis. Synchronisation among individuals was assessed by applying the same procedures to the time series regarding the proportion of filtering worms.

\subsection{Assessment of inter-individual variability}

The impact of inter-individual heterogeneity in filtering activity on the design of experimental plans aiming to assess the effects of environmental factors on filtration was quantified using a bootstrap procedure (Efron, 1979) based on 71 2-h long individual filtration recordings obtained between December 1996 and January 1997 on worms collected within the bay of Banyuls-surMer. This procedure was applied both on the total filtration duration per worm and on the number of filtering events per unit of time. Starting from the 71 means of the initial time series, we randomly generated 228 samples of $N$ means (with $10<N>30$ ). $N$ thus corresponded to the number of worms per replicate. We then randomly generated 100 subsamples of five means. The means and variation coefficients of those subsamples were used to assess the within-treatment variability. 


\section{RESULTS}

\subsection{Calibration}

The determination coefficient of the linear regression model linking individual filtering durations recorded both with the automated system and by classical video-recordings was low when using a minimal surface of two pixels (figure $2 A$, table I). This coefficient correlated positively with minimal surface. Only the ten-pixels value resulted in a linear regression model with an intercept not significantly different from 0 and a slope not significantly different from 1 . This led us to retain this value during the following steps of the calibration.

Results obtained with the automated system correlated poorly with those obtained by classical videorecordings when using a search radius of five pixels (figure 2B, table I). The correlation between activities recorded using the two methods increased with the search radius. Both the fifteen- and the twenty-pixels search radius resulted in regression lines with intercepts not significantly different from 0 and slopes not significantly different from 1 . We used a search radius of 15 pixels during the following steps of the calibration.

There was a poor correlation between the activities recorded by the two methods when considering changes occurring either around the mouth of the tube or around its shadow (figure $2 \mathrm{C}$, table I). Correlation was poor as well when considering only changes around the tube aperture. The scatter was a little bit less important when considering either only the events around the tube shadow or the events concerning simultaneously the tube aperture and its shadow. These results could not be considered as fully satisfactory, which led us to introduce a set of logical conditions designed to relate the events detected by the automated system with real filtering events.

The two first sets both considered the events occurring simultaneously around the tube aperture and around its shadow. They consisted of introducing surface thresholds of 20 and 40 pixels, respectively. These minimal surfaces differed from those mentioned above since they no longer considered elementary but aggregated objects. The correlation between

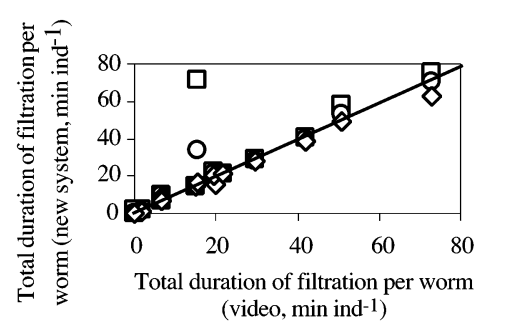

A

\author{
$\square \mathrm{MS}=2$ pixels \\ O MS $=10$ pixels \\ $\diamond \mathrm{MS}=20$ pixels
}

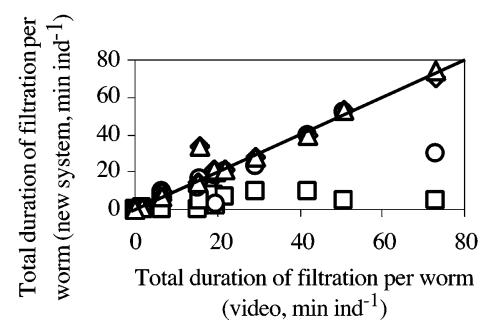

B

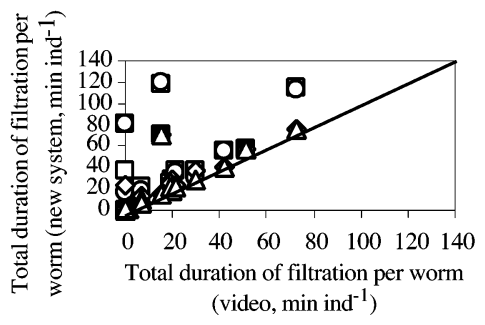

C

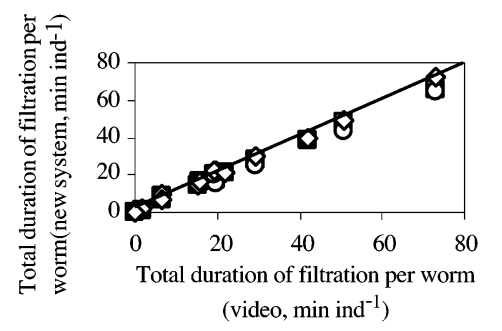

$\square \mathrm{SR}=5$ pixels O $\mathrm{SR}=10$ pixels $\diamond \mathrm{SR}=15$ pixels $\Delta \mathrm{SR}=20$ pixels

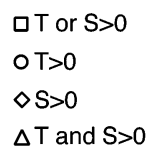

Figure 2. Calibration of the automated system. Comparisons of the total duration of filtration per worm obtained with the automated system when varying the values of the main parameters involved in the post treatment programs and those measured using classical video-recordings. (A) minimal surface, (B) search radius, (C) research sites, (D) logical conditions. T: tube, S: shadow.

the so-obtained activities and those resulting from classical video-recordings are good in both cases (figure 2D, table I). However, both these sets of conditions failed to provide linear regression models with intercepts not significantly differing from 0 and slopes not significantly differing from 1 . We thus introduced an alternative condition regarding the sole changes detected around the shadow of the tube 
Table I. Main characteristics of the linear regression models used during the calibration phase to correlate the measurements carried out with the automated system with those obtained using classical video-recordings.

\begin{tabular}{|c|c|c|c|c|c|}
\hline Parameter (pixels) & $r^{2}$ & Slope & Intercept & Intercept $=0$ & Slope \\
\hline \multicolumn{6}{|l|}{$(\mathrm{SR}=15$, tube and shadow $>0)$} \\
\hline $\mathrm{MS}=2$ & 0.682 & 0.990 & 4.982 & NS & a \\
\hline $\mathrm{MS}=10$ & 0.945 & 0.964 & 1.798 & NS & NS \\
\hline $\mathrm{MS}=20$ & 0.991 & 0.891 & 0.891 & a & c \\
\hline \multicolumn{6}{|l|}{$(\mathrm{MS}=10$, tube and shadow $>0)$} \\
\hline $\mathrm{SR}=5$ & 0.321 & 0.096 & 1.790 & $\mathrm{~b}$ & a \\
\hline $\mathrm{SR}=10$ & 0.711 & 0.626 & 2.871 & NS & NS \\
\hline $\mathrm{SR}=15$ & 0.945 & 0.964 & 1.798 & NS & NS \\
\hline $\mathrm{SR}=20$ & 0.950 & 0.996 & 1.535 & NS & NS \\
\hline \multicolumn{6}{|l|}{$(\mathrm{MS}=10, \mathrm{SR}=15)$} \\
\hline Tube or shadow $>0$ & 0.271 & 0.906 & 28.284 & NS & $\mathrm{b}$ \\
\hline Tube $>0$ & 0.278 & 0.956 & 23.838 & NS & $\mathrm{b}$ \\
\hline Shadow $>0$ & 0.650 & 0.933 & 9.457 & NS & NS \\
\hline Tube and shadow $>0$ & 0.682 & 0.990 & 4.982 & NS & a \\
\hline \multicolumn{6}{|l|}{$(\mathrm{MS}=10, \mathrm{SR}=15)$} \\
\hline Tube and shadow $>20$ & 0.996 & 0.910 & 0.793 & b & c \\
\hline Tube and shadow $>40$ & 0.994 & 0.879 & 0.600 & c & c \\
\hline Tube and shadow $>40$ or shadow $>80$ & 0.995 & 0.973 & 0.809 & NS & NS \\
\hline
\end{tabular}

MS: minimal surface, SR: search radius. NS: not significant.

a $0.01<P<0.05$.

b $0.001<P<0.01$.

c $P<0.001$.

aperture within the third set of conditions. This resulted in a highly significant linear regression model between observed and predicted activities with an intercept not significantly different from 0 and a slope not significantly different from 1 . This set of conditions was thus used during the validation phase.

\subsection{Validation}

Correlation between observed and predicted activities was high for all the four validation experiments (figure 3, table II). Intercepts of the regression models significantly differed from 0 during two experiment whereas slopes significantly differed from 1 during three experiments. When pooling the results of all the validation experiments, there was a highly significant correlation between predicted and observed activities. The intercept did not significantly differ from 0 but the slope significantly differed from 1, partly due to low scatter between predicted and observed activities. The simultaneousness of the filtering events detected by the two methods was good as well, with only some filtration events shorter than 1 min not detected by the automated system. Overall, we considered that the validation phase was satisfactory and therefore

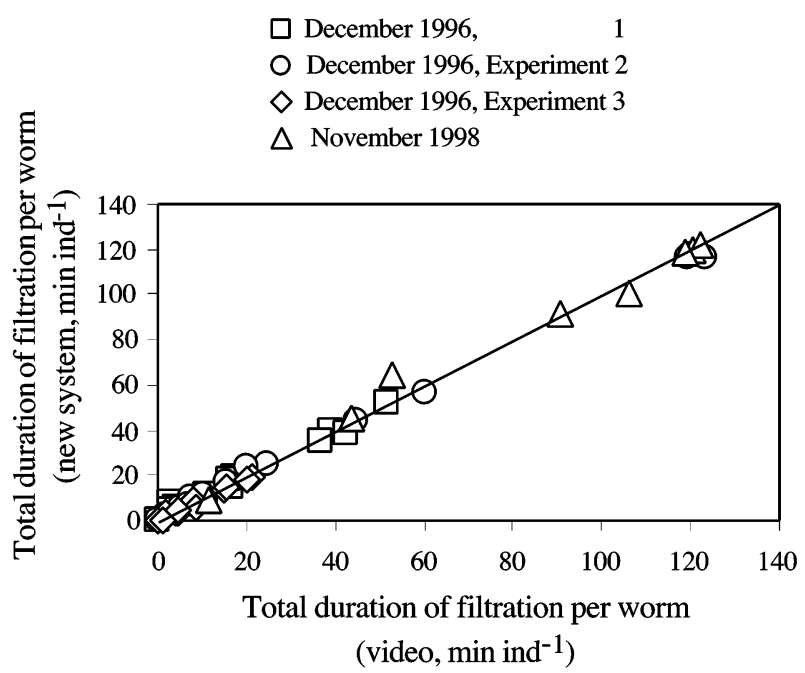

Figure 3. Validation of the automated system. Comparison of the total duration of filtration per worm detected using both the automated system (with the parameters determined during the calibration phase) and classical video-recordings. 
Table II. Main characteristics of the linear regression models used during the validation phase to correlate the measurements carried out with the automated system to those obtained using classical video-recordings.

\begin{tabular}{llllllll}
\hline & Exp. & $\mathrm{N}$ & $r^{2}$ & Slope & Intercept & Intercept $=0$ & Slope $=1$ \\
\hline Dec. 1996 & 1 & 15 & 0.987 & 0.949 & 1.293 & NS & NS \\
Dec. 1996 & 2 & 15 & 0.998 & 0.951 & 1.377 & NS & a \\
Dec. 1996 & 3 & 15 & 0.983 & 0.914 & 0.085 & a & \\
Nov. 1998 & 11 & 0.988 & 0.972 & 2.945 & $\mathrm{~b}$ & $\mathrm{a}$ & \\
Pooled & 56 & 0.996 & 0.980 & 0.576 & NS & a & \\
\hline
\end{tabular}

NS: Not significant.

a $0.01<P<0.05$.

b $0.001<P<0.01$.

c $P<0.001$.

used the so-defined set of parameters and conditions to infer filtering activity in $D$. arietina.

\subsection{Filtering activity patterns in $D$. arietina}

During all three experiments, the variability in filtration patterns among individuals was important. The total filtration durations per worm ranged between 52 and $1155 \mathrm{~min}, 38$ and $1306 \mathrm{~min}$, and 93 and 1164 min for the September 8, 9, and 10 experiments, respectively. The number of filtration events per single worm and per experiment ranged between 25 and 93, 12 and 82, and 28 and 67 for the September 8, 9, and 10 experiments, respectively. The average durations of each filtration event were between 2 and 46 $\min , 2$ and $109 \mathrm{~min}$, and 3 and $34 \mathrm{~min}$ for the September 8, 9, and 10 experiments, respectively. The relationships between total duration of filtration per worm, and number of filtration events or average duration of each filtration event are given in figures $4 A$ and $4 B$, respectively. The total filtration duration correlated positively with the average duration of each filtration event but not with the number of those events. For 20 out of the 35 worms under study (one worm was discarded since it featured no activity at all during the September 9 experiment), there was no evidence for temporal trend in filtering activity. There was no consistent pattern (i.e. constant decrease or increase of filtering activity during the overall length of the experiment) for the other 15 worms.

The four main types of individual filtration patterns observed during the present study are presented in figure 5. Pattern 1 is characterised by the constant succession of short (i.e. less than 5 min.) filtration events, which results in a strong periodicity around a time-period close to $30 \mathrm{~min}$. This pattern was associated with 23 of the 35 worms studied. Pattern 2 corresponds to a modification of the first one through the introduction of longer resting periods. The periodic signal corresponding to the succession of short filtration events, although still present, is thus strongly altered. This pattern was associated with 7 of the 35 worms under study. Patterns 3 and 4 are both characterised by a total absence of periodicity. In pattern 3, this absence results from low filtration. This pattern was associated with only 1 out of the 35 worms under study. In pattern 4 , the absence of periodicity is linked to the coexistence of both short
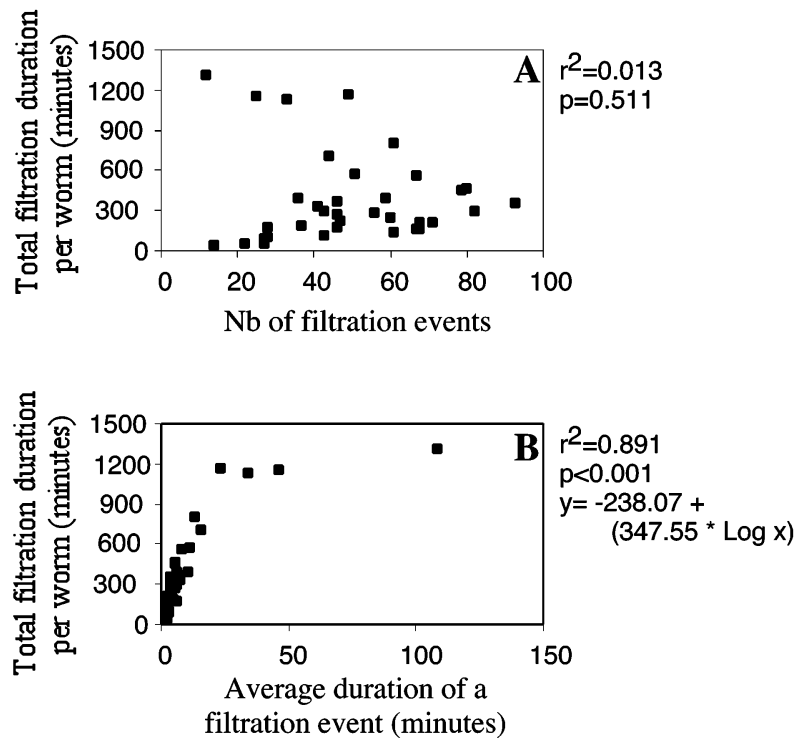

Figure 4. Relationships between total filtration duration per worm and the number of filtration events per worm (A), and the average duration of a filtration event (B). Data are pooled for all three experiments involving worms collected off Argelès-sur-Mer. 
Filtration pattern
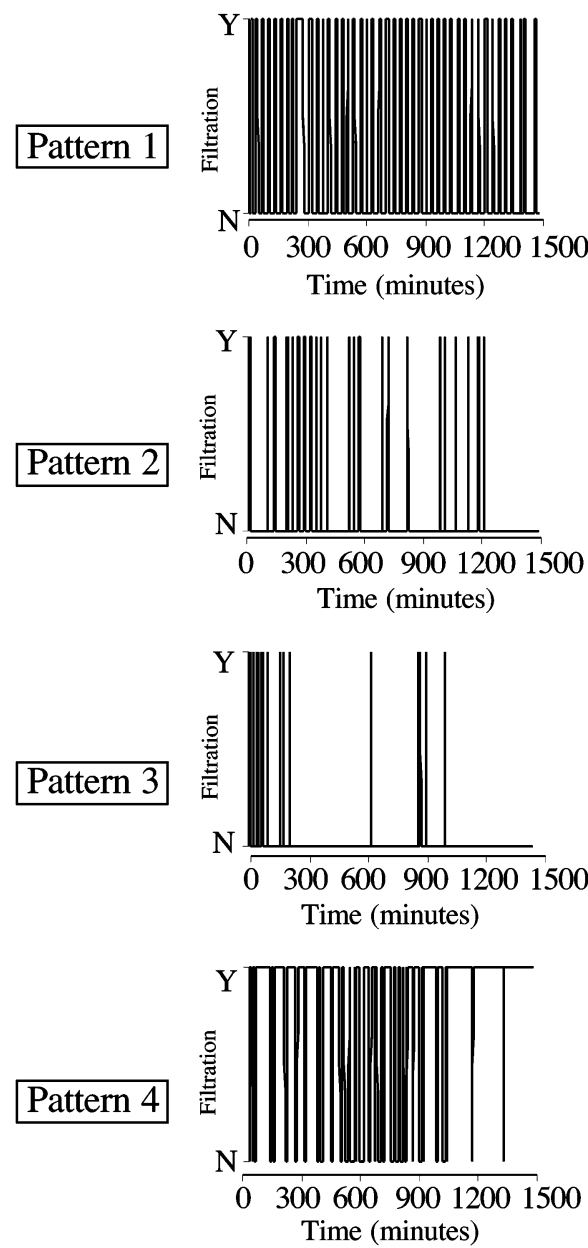

Periodogram
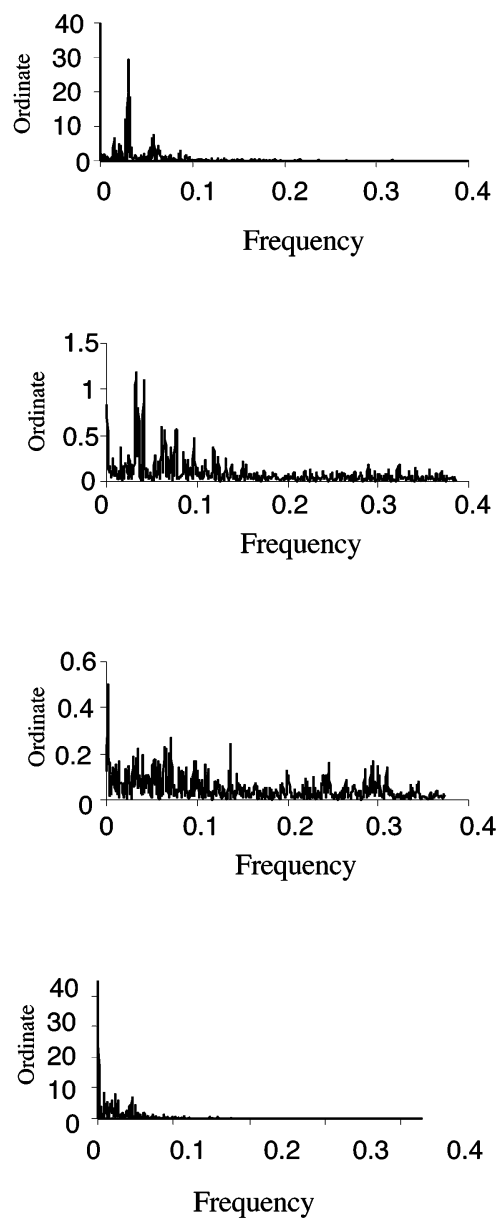

Figure 5. Presentation of the four main filtration patterns recorded during the three experiments involving worms collected off Argelès-sur-Mer together with the corresponding periodograms. Y: filtration, N: no filtration.

and long filtration events. This last pattern was associated with the worms featuring the highest filtering activity ( 4 of the 35 worms under study).

Temporal changes in the proportion of filtering worms are presented in figure 6 together with the corresponding periodograms for each of the three experiments involving worms collected off Argelèssur-Mer. Maximal proportions of filtering worms were of $66.7,66.7$ and $81.8 \%$ for the September 8, 9, and 10 experiments, respectively. These values were rather rare and these proportions usually remained close to the average value for the whole experiment (i.e. $19.5,26.8$ and $39.2 \%$ for the September 8, 9, and
10 experiments, respectively). There was no evidence for any temporal trend. Spectral analyses carried out for the September 8 and 10 experiments did not reveal any obvious periodicity in temporal changes of the proportion of simultaneously filtering worms. This pattern was less clear for the September 9 experiment.

\subsection{Assessment of inter-individual variability}

Results of the bootstrap procedures applied both to total filtration duration and to the number of filtra- 


\section{Filtration pattern}

Periodogram
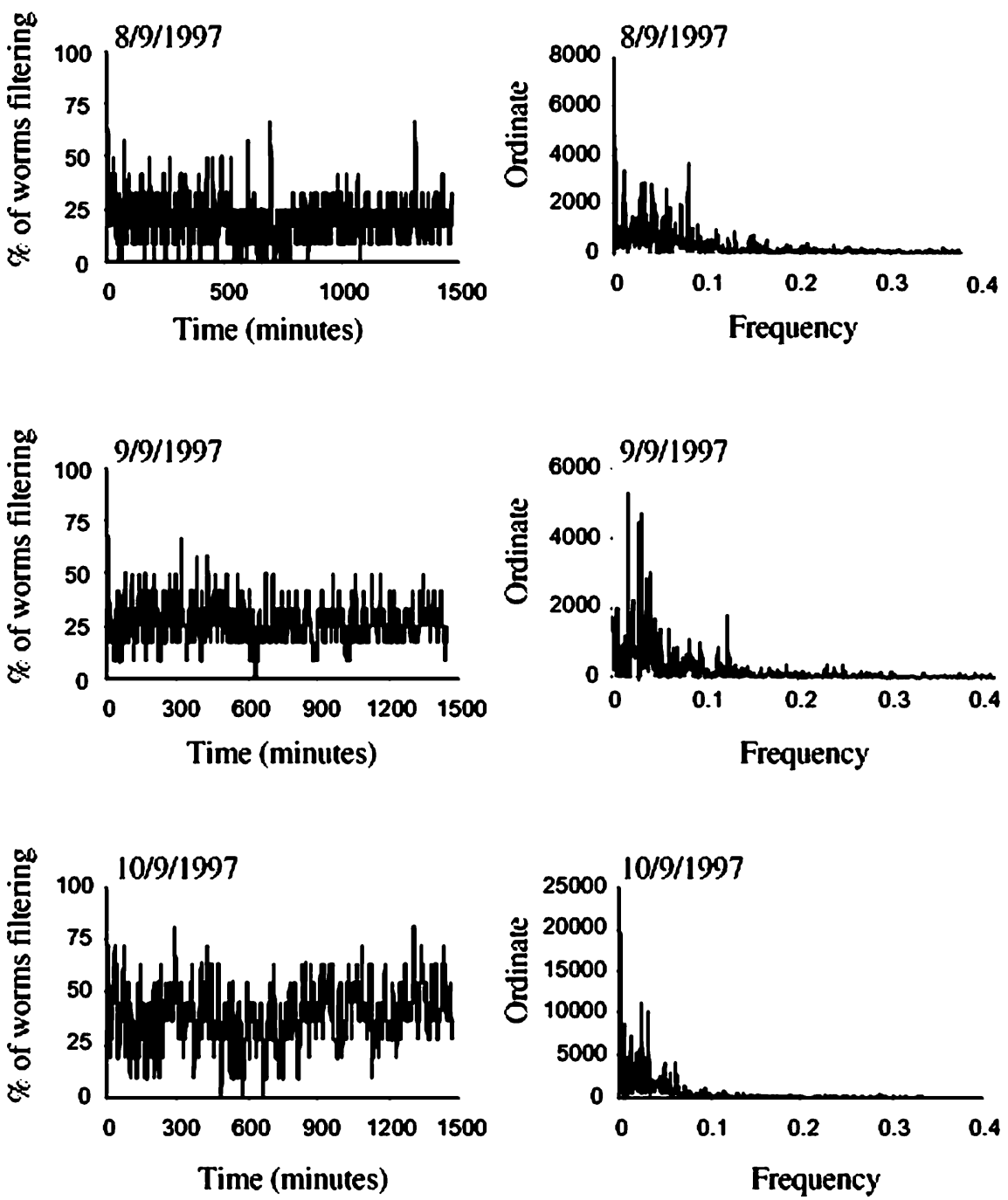

Figure 6. Temporal changes in the number of filtering worms (together with corresponding periodograms) during the three experiments involving worms collected off Argelès-sur-Mer.

tion events per unit of time are presented in figure 7. For both of these parameters the means resulting from the bootstrap came closer to the average values characterising the activity of the initial population as the number of worms per replicate increased. Corresponding variation coefficients decreased as the number of worms per replicates increased. Variation coefficients remained relatively high (i.e., about $20 \%$ ) even when using as much as 30 worms per replicate.

\section{CONCLUSION}

4.1. The automated image analysis system in comparison with other existing devices

First studies regarding larval photoresponse (Young and Chia, 1982; Marsden, 1984 and 1990), or swimming kinetics (Clark and Hermans, 1976) have either been based on visual observations or on high-speed 
Total filtration duration per worm
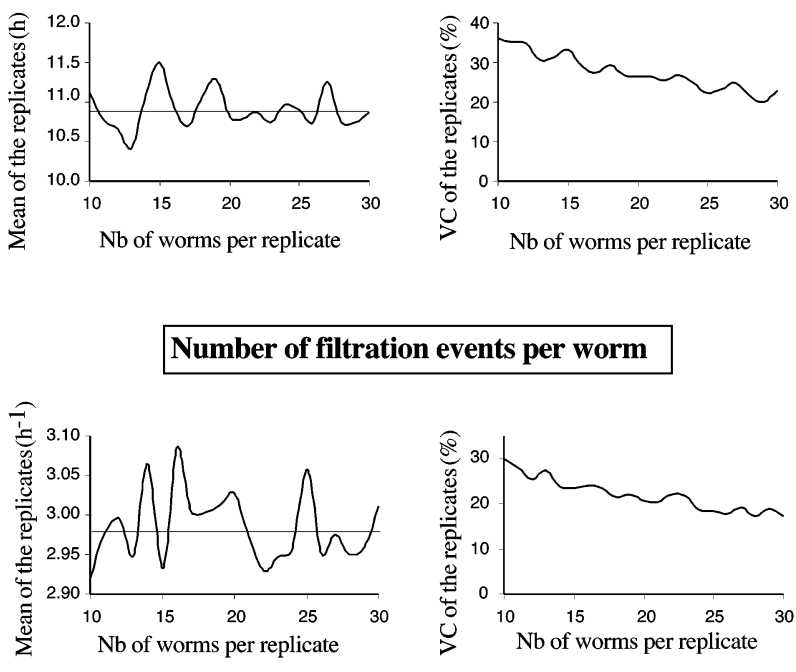

Figure 7. Results of the bootstrap procedures assessing the effect of inter-individual heterogeneity on the within-treatment variability of experimental plans designed to assess the effect of environmental factors. Relationship between the number of worms per replicate and the mean and variation coefficients of both the total filtration duration and the number of filtration events per worm. Horizontal lines correspond to the means of the initial populations (see text for details). VC: variation coefficients.

cinematography. Development of video and small computers later allowed for the introduction of track analysis. In most cases, tapes were played back frame by frame and analyzed manually. Those techniques were refined to allow for $3 \mathrm{D}$ analysis using appropriate optic devices (Boisclair, 1992; Young and Getty, 1987). They have been used in different research fields until recently (Wong et al., 1986; Boudreau et al., 1991; Saiz and Alcaraz, 1992; Hughes and Atkinson, 1997), sometimes in association with fluorescent labelling of small organisms such as larvae (Jonson et al., 1991).

Another approach consists of playing back and digitizing the videotapes after the experiment, the soobtained signal being then processed with specific softwares. The first systems of this kind were associated with minicomputers. Lang et al. (1979) studied the responses to light variations of Balanus imprecisus nauplii using a computerized procedure developed byGreaves (1975). The same system was later used for the measurement of horizontal swim- ming and vertical sinking velocities of Capitella capitata larvae (Butman et al., 1988). Rapid technological improvements then allowed for the use of microcomputers, and the reduction of processing time. This resulted in a real-time digitizing and processing of either the recorded videotapes (Ramcharan and Sprules, 1989) or even the video signal when directly transmitted to the computer (Bakchine-Huber et al., 1992; Davis et al., 1996).

The in situ deployment of such systems remains however problematic due to the necessity of a physical connection between the video sensor and the computer, or to videotape storing capacities. One of the main advantages of our system is that most of the computations are carried out in real-time by the processor associated with the sensor, which makes it fully autonomous during the whole monitoring period. Moreover, the system does not store full images but only numerical objects computed from differences between images, which increases the maximal possible duration of monitoring session. These two advantages open up important possibilities for in situ deployment. In addition, the sensor unit may start specific sampling procedures depending on real-time activity measurements.

\subsection{The use of the automated system to infer filtration activity in $D$. arietina}

There was always a strong correlation between activities recorded using either classical video analysis or our automated system. This suggests that the automated system provides satisfactory estimates of filtration activity in D. arietina. However, the slopes or the intercepts of the linear regression models linking activities recorded using the two techniques differ significantly from 1 and 0 , respectively in three out of four experiments. This result is partly due to the strong fit of these linear regression models. Nevertheless we believe that it also reflects a true underestimation of filtration when using the automated system. Such an underestimation could be associated with filtration events shorter than 1 min and taking place between two consecutive image acquisitions by the video sensor.

We used the results of the three validation experiments carried out during December 1996 to infer 
the possible bias resulting from such short filtration events. During these experiments, filtration events shorter than $30 \mathrm{~s}$ and comprised between 30 and $60 \mathrm{~s}$ accounted for 10.8 and $16.3 \%$ of the total number of filtration events, respectively. These two kinds of events accounted for 0.7 and $2.6 \%$ of the total filtration duration, respectively. A simple probability computation shows that short filtration events not detected by the automated system would account for about $12 \%$ of the total number of filtration events and $1.1 \%$ of the total filtration duration. This last figure may explain the slight underestimation of filtration duration when using the automated system.

It is also important to point out that the calibration procedure was solely based on total filtration durations, whereas most of the error linked to the occurrence of short filtration events is related to the number of filtration events. Moreover, the average duration of each filtration event may vary depending on worms and experiments. Filtration events are usually longer in worms with high activities than in worms with low activities. The underestimation of the number of filtration events is thus more important in worms featuring low filtration. This is well illustrated by the results of the November 1998 experiments (average filtration duration of 90 min against only 23 min for the three other validation experiments) during which non detected filtration events corresponded to only 2.1 and $0.1 \%$ of the number of filtration events and of the total filtration duration, respectively.

During the present study, the frequency of picture acquisition was mainly limited by the speed of the microprocessor and the amount of information that could be stored on the memory board of the sensor. Since then, the image analysis system has been improved through the use of a new sensor with higher resolution, a new microprocessor, and the incorporation of a new storing device. These developments allow for picture acquisition and treatment every 0.5 s. This should thus no longer constitute a problem during future studies regarding filtering activity in $D$. arietina.

\subsection{Characterisation of filtering activity in $D$. arietina}

This is the first study reporting on filtration activity patterns in $D$. arietina. Besides the test of the auto- mated image analysis system, we also wanted to collect information on the standard filtration of $D$. arietina to develop appropriate experimental plans aiming at assessing the effects of environmental factors on filtration. This is why we have decided to work in the absence of any strong stimulus (e.g., food, hydrodynamism, etc...).

Filtering activity consists in a succession of filtration and resting events, which can be characterised by total filtration duration and by the number of filtration events per unit of time. Our results show that changes in total filtration duration are not caused by an increase in the frequency of filtration events but rather by an augmentation of the average duration of those events.

Due to these interactions and to high inter-individual variations in total filtration durations, individual patterns of filtration also feature high heterogeneity. It is nevertheless possible to define several types of patterns and to relate them to total filtration duration. For the animals collected off Argelès-sur-Mer during October 1997, the dominant pattern (pattern 1) corresponds to a repetition of short (i.e., $<5 \mathrm{~min}$ ) filtration events occurring approximately every $30 \mathrm{~min}$. This pattern can be modified either by the introduction of longer resting events (patterns 2 and 3) or, on the contrary, by the introduction of longer filtration events (pattern 4). In both cases this results in an attenuation or even a loss of the periodicity characterising pattern 1. Pattern 4 is clearly associated with the most active worms by opposition to pattern 3 . Each experiment seems largely dominated by a single pattern of filtration. For example, worms collected within the bay of Banyuls-sur-Mer during October 1998 mainly followed pattern 4.

Even in those experiments during which most of the worms have shown a strong periodicity in their filtration (e.g., Argelès-sur-Mer, September 1997), we have not been able to collect any evidence for synchronicity among individuals. Temporal changes in the proportion of filtering worms were indeed low in amplitude and did not show any periodicity. This lack of synchronicity may partly result from the fact that our experiments were carried out in the absence of any strong external stimulus. 


\subsection{Consequences of inter-individual variability for the design of experimental plans aiming at assessing the impact of environmental factors on filtration in $D$. arietina.}

We are now interested in experimentally assessing the impact of environmental factors on filtration in $D$. arietina. This objective requires appropriate experimental plans. In its present form, the automated image analysis system does not allow for the simultaneous monitoring of several batches of worms (i.e., replicates). This problem could be solved by placing the video sensor on automated $\mathrm{X}-\mathrm{Y}$ translator as already done for the automated tracking of planktonic larvae (Duchêne and Nozais, 1994). Together with reduction in processing time, this would allow following simultaneously the activity of different batches of worms submitted to different treatments. However, this development would probably prove insufficient, when studying filtration in D. arietina, due to high inter-individual variability. Results of the bootstrap procedure indeed show that variation coefficients corresponding to within-treatment variability are close to $20 \%$. Such variability would strongly limit the ability of the association of experimental plans based on replication to detect significant treatment effects. A possibility to overcome this difficulty would be to submit the same batch of worms to successive values of the tested parameters and then to use pairwise comparison tests to statistically infer the effects of those treatments. Such an experimental design has already been applied to the study of the effect of light on larval swimming (Lang et al., 1979). It requires the constancy of individual standard activity during the entire experiment. According to our results, this hypothesis seems to be fulfilled for experiment durations up to $24 \mathrm{~h}$ in the case of D. arietina.

\section{REFERENCES}

Achituv, Y., Yamaguchi, T., 1997. Water pumping in the penduculate barnacle Conchoderma auritum. J. Mar. Biol. Ass. UK 77, 1073-1082.

Bakchine-Huber, E., Marion-Poll, F., Pham-Delegue, M.H., Masson, C., 1992. Real-time detection and analysis of the exploratory behavior of small animals. Naturwissenschaffen 79, $39-42$.

Boisclair, D., 1992. An evaluation of the stereocinematographic method to estimate fish swimming speed. Can. J. Fish. Aquat. Sci. 49, 523-531.

Boudreau, B., Simard, Y., Bourget, E., 1991. Behavioural responses of the planktonic stages of the american lobster Homarus americanus to thermal gradients and ecological implications. Mar. Ecol. Prog. Ser. 76, 13-23.

Butman, C.A., Grassle, J.P., Buskey, E.J., 1988. Horizontal swimming and gravitational sinking of Capitella sp. I (Annelida: Polychaeta) larvae: implications for settlement. Ophelia 29, 43-57.

Clark, R.B., Hermans, C.O., 1976. Kinetic of swimming in softbodied polychaetes. J. Zool. Lond. 178, 147-159.

Davey, G.T., Watson, P.G., Bruce, R.H., Frickers, P.E., 1990. An instrument for the monitoring and collection of the vented burrow fluid of benthic infauna in sediment microcosms and its application to the polychaetes Hediste diversicolor and Arenicola marina. J. Exp. Mar. Biol. Ecol. 139, 135-149.

Davis, C.S., Gallager, S.M., Marra, M., Stewart, W.K., 1996. Rapid visualization of plankton abundance and taxonomic composition using the video plankton recorder. Deep Sea Res. 43, 1947-1970.

DeVilliers, C.J., Hodgson, A.N., 1993. The filtration and feeding physiology of the infaunal estuarine bivalve Solen cylindraceus Hanley 1843. J. Exp. Mar. Biol. Ecol. 167, 127-142.

Duchêne, J.C., Nozais, C., 1994. Light influence on larval emission and vertical swimming in the terebellid worm Eupolymnia nebulosa (Monagu, 1818). In: Dauvin J.C., Laubier L., Reish D.J. (Eds.), Actes de la $4^{\mathrm{e}}$ Conférence Internationale des Polychètes, Mem. Mus. Hist. Nat., Paris, pp. 405-412.

Efron, B., 1979. Bootstrap methods: Another look at the Jackknife. Ann. Stat. 7, 1-26.

Grassle, J.P., Butman, C.A., 1989. Active habitat selection by larvae of the polychaetes, Capitella spp. I and II, in a laboratory flume. In: Ryland S.J., Tyler P.A. (Eds.), Reproduction, Genetics and Distribution of Marine Organisms. 23 ${ }^{\text {rd }}$ European Marine Biology Symposium, Olsen \& Olsen, Fredensborg, pp. 107-114.

Greaves, J.O., 1975. The bugsystem: the software structure for the reduction of quantized video data of moving organisms. Proceedings of the IEEE, 63.

Grémare, A., 1987. Feeding, tube building and particle-size selection in the terebellid polychaete Eupolymnia nebulosa. Mar. Biol. 97, 243-252.

Grémare, A., Amouroux, J.-M., Vétion, G., 1998a. Long term comparison of macrobenthos wihin the soft bottoms of the Bay of Banyuls-sur-Mer (northwestern Mediterranean Sea). Neth. J. Sea Res. 40, 281-302.

Grémare, A., Sarda, R., Medernach, L., Jordana, E., Pinedo, S., Amouroux, J.-M., Martin, D., Nozais, C., Charles, F., 1998b. On the dramatic increaseof Ditrupa arietina O.F. Müller (Annelida:Polychaeta) along both the French and the Spanish Catalan coasts. Est. Coast. Shelf Sci. 47, 447-457.

Häder, D.P., Vogel, K., 1991. Interactive image analysis system to determine the motility and velocity of cyanobacterial filaments. J. Biochem. Biophys. Meth. 22, 289-300. 
Hill, J., 1976. Natural food, foregut clearance rate and activity of the crab Scylla serrata. Mar. Biol. 34, 109-116.

Hughes, D.J., Atkinson, R.J.A., 1997. A towed video survey of megafaunal bioturbation in the north-eastern Irish Sea. J. Mar. Biol. Ass. UK 77, 635-653.

Jonson, P.R., André, C., Lindegarth, M., 1991. Swimming behaviour of marine bivalve larvae in a flume boundary layer flow: evidence for near-bottom confinment. Mar. Ecol. Prog. Ser. 79, 67-76.

Lang, W.H., Forward Jr, R.B., Miller, D.C., 1979. Behavioural responses of Balanus imrovisus nauplii to light intensity and spectrum. Biol. Bull. 157, 166-181.

Marsden, J.R., 1984. Swimming in response to light by larvae of the tropical serpulid Spirobranchus giganteus. Mar. Biol. 83, $13-16$.

Marsden, J.R., 1990. Light responses of the planktonic larva of the serpulid polychaete Spirobranchus polycerus. Mar. Ecol. Prog. Ser. 58, 225-233.

Medernach, L., Jordana, E., Grémare, A., Nozais, C., Charles, F., Amouroux, J.-M., 2000. Population dynamics, secondary production and calcification of Ditrupa arietina O.F. Müller (Annelida:Polychaeta) within the Bay of Banyuls-sur-Mer (Western Mediterranean). Mar. Ecol. Prog. Ser. 199, 171-184.

Morton, B., 1983. Feeding and digestion in Bivalvia. In: Wilbur, K.M. (Ed.), The Mollusca. Academic Press, New York, pp. $65-147$.

Nozais, C., Duchêne, J.C., 1996. Larval buyoancy and release from polychaete egg masses. J. Exp. Mar. Biol. Ecol. 203, 209-222.

Nozais, C., Duchêne, J.C., Bhaud, M., 1997. Control of position in the water column by the larvae of Poecilochaetus serpens, (Polychaeta): The importance of mucus secretion. J. Exp. Mar. Biol. Ecol. 210, 91-106.

Ramcharan, C.W., Sprules, W.G., 1989. Preliminary results from an inexpensive motion analyser for free-swimming zooplankton. Limnol. Oceanogr. 34, 457-462.

Saiz, E., Alcaraz, M., 1992. Free-swimming behaviour of Acartia clausi (Copepoda:Calanoida) under turbulent water movement. Mar. Ecol. Prog. Ser. 80, 229-236.

Thorin, S., Bourdages, H., Vincent, B., 1998. Study of siphon activity in Mya arenaria (L.) in the intertidal zone by means of an underwater video camera. J. Exp. Mar. Biol. Ecol. 224, 205-224.

Trager, G.C., Coughlin, D., Genin, A., Achituv, Y., Gangopadhyay, A., 1992. Foraging to the rhythm of ocean waves: porcelain crabs and barnacles synchronize feeding motions with flow oscillations. J. Exp. Mar. Biol. Ecol. 164, 73-86.

Trager, G.C., Hwang, J.S., Stricker, J.R., 1990. Barnacle suspension-feeding in variable flow. Mar. Biol. 105, 117-127.

Wong, C.K., Ramcharan, C.W., Sprules, W.G., 1986. Behavioral response of an herbivorous calanoid copepod to the presence of other zooplankton. Can. J. Zool. 64, 14221425.

Young, C.M., Chia, F.S., 1982. Ontogeny of phototaxis during larval development of the sedentary polychaete Serpula vermicularis (L.). Biol. Bull. 162, 457-468.

Young, S., Getty, C., 1987. Visually guided feeding behaviour in the filter-feeding cladoceran, Daphnia magna. Anim. Behav. 33, $541-548$. 